\title{
A Study of Leisure Sports Majors' Innovation Ability Evaluation on the Basis of Computer Use
}

\author{
Li Zhishuang \\ School Attached to Shijiazhuang Tiedao University, Shijiazhuang, Hebei, China, \\ 050000 \\ lizhishuang123@163.com
}

\begin{abstract}
At present, artificial intelligence has become an important part of people's life. Meanwhile, people's health consciousness and demands for modern leisure sports have improved. Based on the technology of artificial intelligence, this paper is to stldy the evaluation of leisure sports majors' innovation ability which stays in relat vely low level but with great potential. After researching and analyzing the status of leisure sports majors' innovation ability at home and abroad, the author defined the standard of gray rates, set gray evaluation index, analyzed the gray evaluation model and concluded that students in HeBei Institute of Physical Education have good innovation abilities. This paper which laid a foundation for studies of relevant theories and practices is a pioneering work for innovation ability evaluation.
\end{abstract}

Keywords: leisure sports; innovation ablity; evallation; gray rates; gray evaluation model

\section{Introduction}

The development of Artificial Intelligence(AI for short) has lead to significant changes in people's modes of thinking as well as of production and life. Attached to the advent of scientific and technølogical revolution, AI is based on the application of computer and has the features of extensiveness, progressiveness and potentiality. [1] It was in the 1950s and 1960s that AI began to rise which was based on heuristics and neural networks. In the 1970s, it began to thrive From 1990s, especially, AI began to combine the use of knowledge and had invoived into a higher-level technology. [2] Meanwhile, the advancing of information evolation has exerted directed impact to economic development and people's thinking mode. This paper is to discuss the application of AI in sports evaluation based on practical work. As a new form of sports activity, Leisure Sports, philosophically, focuses on the free and initiative feature of sports participation process. [3] Form the features of sports; Leisure Sports includes both physical activities and the appreciation of sports game. From the angle of pedagogy, Leisure Sports is a lifestyle for human development. With its development, Leisure Sports has developed the features that taking physjcal and mental health as the main purpose, the aged and women as the main target group, personalization as the main service orientation and leisure and entertainment as the major trend. It is initiative and spontaneous which is to ease your mind and body via spontaneous activities rather for raking and awards through intensive training, and to enjoy yourself and seek spiritual rather material pleasure during activities. [4] Leisure Sports has undergone changes from focusing on body-building instruction and management to focusing on fostering personnel to meet the social needs, from standing still to keeping pace with the times, from sticking to traditional projects to developing market-oriented as well as emerging projects, with facilities and teaches' qualities improved. The development of Leisure Sports leads a growing trend in which people's great demand for leisure activities, continuous social and economic development as well 
as the improving of people's living standard and consumption capacity, in the age of tourism for all, has directly led to greater demands for higher-level physical qualities as well as activities of body-building and entertainment. [5] This paper is to propel the development of Leisure Sports and to make better model evaluations and theoretical studies and to lay a foundation for similar studies and to publicize the significance of AI on sports innovation and its own meaning.

\section{Research Status of Leisure Sports Majors' Innovation Ability}

\subsection{Foreign Students Leisure Sports Innovation Ability Status}

Foreign students' leisure sports innovation ability has three features:

(1) Combining innovation-job majors with social reality

(2) Combining fostering of professionals with active market demand

(3) Combining sports expertise with hands-on practices

Examples as follows [6]:

Table 1. Foreign Students' Leisure Sports Innovation Ability Status Table

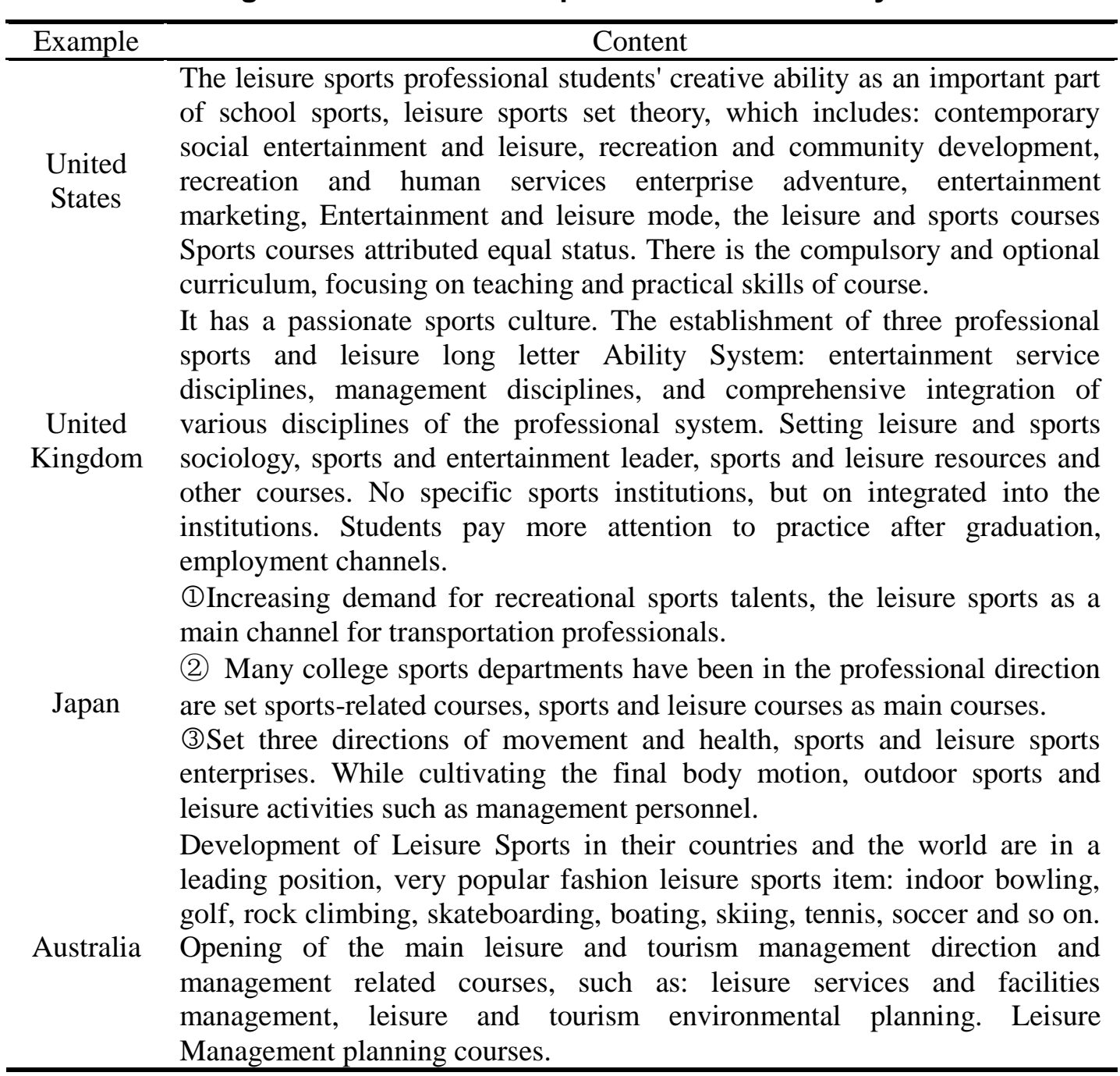

Foreign leisure sports courses, mostly, are theory-oriented. Professional courses, mainly in discipline and module with the form of compulsory and optional curriculum, are systematic, comprehensive, spontaneous and extensive. They focus not only on theory, 
but more on practice to meet the needs of students as well as other users. [7] Professional sports courses are mostly designed into compound ones, such as courses with physical, economic and management features. Leisure sports courses, leisure activities and various sports are of great importance in publicizing and managing the development and innovation of Leisure Sports. They greatly unleashed its market potential and brought the practical and innovative nature into full play while cultivated students' and other user' sense of responsibility, social responsibility, mission, and service.

\subsection{Domestic Students' Leisure Sports Innovation Ability Status}

China's leisure sports development started late with a slow pace and now is in the primary stage. Although the mass leisure major has been included in higher education with some success in theory, practice and talent fostering, problems still remain.

Examples as follows [8]:

Table 2. Domestic Students' Leisure Sports Innovation Ability Status Jable

\begin{tabular}{|c|c|}
\hline project & Content \\
\hline theory & $\begin{array}{l}\text { Humanistic perspective: dependent on market needs emphasizing the } \\
\text { people-oriented, and open-minded; } \\
\text { On the Subject Setting: development of the times, the needs of } \\
\text { society-oriented, rich theoretical discipline, conduct special research, the } \\
\text { construction of service system promote the exchange and development, } \\
\text { in line with reasonable curiculum sysen construction and social } \\
\text { development, enrichment teacher resources }\end{array}$ \\
\hline practice & $\begin{array}{l}\text { Courses focus on applications, comprehensive and practical, to the } \\
\text { humanities, social sciences and natural sciences various disciplines, } \\
\text { increase the proportion of elective courses, refresher courses types. }\end{array}$ \\
\hline $\begin{array}{c}\text { talent } \\
\text { development }\end{array}$ & $\begin{array}{l}\text { According to Mallow's Gierarchy of needs theory need more } \\
\text { individualized attention to students, the market demand-oriented and } \\
\text { professional development of the requirements to build the knowledge } \\
\text { structure of leisure sports professionals to cultivate a strong combat } \\
\text { capability, create complex high-level talents. }\end{array}$ \\
\hline
\end{tabular}

Based on the use of computer, China has come up with its core idea to improve students' leisure sports innovation ability, namely, to take it as an industry. That is to ensure its advantage of low cost, great potential, high correlation and wide radiation range, while integrate the public benefits with its commercial feature and seek both economic and social interests to meet the needs of national welfare. Especially since 1990s, China's sports industry saw numerous ups and downs. [9] Its constant progress and improvement during the integration with market have greatly raised people's demands and objectives. In choo ing proper policies for leisure sports industry, attention should be paid to protect competition and curb monopoly, to deepen the reform of internal organizations, to promote scale operation and non-balance regional development of leisure sports industry. Based on such strategies, it is concluded that we should give priority to the leading sectors so as to guide and propel other sectors.

China has carried out strong measures to facilitate the study of leisure sports on the basis of the use of computer. First is financial support and taxation reduction, which is to develop leisure sports industry and promote physical and mental health of our citizens through financial support, subsidy, tax reduction and exemption, etc. Second is financing support. [10] Facing the problems of fund shortage, low development level and narrow found rising channel, we should develop the leisure sports industry through support of financial institutions, introducing Venture Capital and financing of securities administration departments. Third is preferential use of land and national assets. We 
should make land assignments as well as encourage those with richer land resources to participant in leisure sports construction, which to some extend advanced the development of leisure industry. Forth is policies to guide consumption. Which is to take leisure sports consumption as a healthy one under the background of China's consumption mode transition to promote industrial development as well as to keep consumer behaviors in proper manners?

\subsection{Existing Problems in Leisure Sports Majors' Innovation Ability.}

(1) Leisure sports majors' innovation ability cultivation does not in line with the social needs. Namely, current curriculum does not have a clear orientation which can neither make its own advantages to full play nor comply with the needs of social development [9].

(2) With less outstanding features. At universities, there are many kinds of courses. However, owing to inadequate knowledge of innovation ability building and social needs, these courses, with no hot courses and clear direction, directly ignore the cultivation of innovation ability and independent practice ability of users and cannot keep up with the social development.

(3) Few, short and monotonous courses. Conditions and features of leisure sports education vary from region to region. Needs and standaras to examine people's all-round ability will always change to conform to market situation. What's more, such abilities are constantly changing and regulating themselves. 101 Therefore students did not truly understand the basic theory concerning leisure sports, body-building instruction and sports management. They also did not grasp the sports skins and scientific research as well as hands-on abilities.

(4) Limited facilities and equipment and outdated Teâching content. Target of talent cultivation are not concrete; curriculum has no outstanding features; employment status of sports majors are rather severe abilities of teachers and teaching materials cannot meet the needs of students. Aesthetic ability cultivation is not involved; students' appreciation ability has not been improved; students do not enjoy them.

(5) Heath concept as well as sports awareness have not been established, nor correct sports value. Studems do not have the ability to correctly judge and comment on behaviors in sports. Meanwhile, students pay inadequate attention to their own innovation awareness and cannot see their own deficiency as well as the gap with others. Mostly, the cultivation of users' innevation abilities remains in superficial level with less attention and efforts attaching to it.

(6) The assessing standards of users' innovation ability focus only on common point rather differences, in which scores are of greater importance than practical work. Intentions are hard to catch comprehensively, correctly and systematically.

(7) Scale of leisure sports industry are small with outdated facilities, improper planning and low technology content in sports training and teaching.

\section{Research on Intelligent Evaluation of Leisure Sports Majors' Innovation Ability}

This paper is based on gray evaluation model. The theory of gray evaluation model is actually to use known information to identify unknown information. It is a theory between known and unknown. [11] It has the nature of progressiveness, systematic, operability, scientific and timeliness. The theory itself is unique and abstract as intermediary information, which is beneficial for analyzing imprecise and disordered data using both quantitative and qualitative methods. Main process as follows: 


\subsection{Analysis of the Factors of Leisure Sports Majors' Innovation Ability.}

Innovation ability can be classified into three main types. The first one is technological innovation ability, which covers the ability to input innovative resources, the ability of research and development as well as incubation, the ability of innovation diffusion and the ability of innovator. The second one is institutional innovation ability, which includes industry policy innovation, park management innovation, incentive mechanism innovation and industry internal system innovation. The third one is supporting innovation ability, which contains intelligence supporting ability, economy and technology supporting ability, infrastructure supporting ability, information resource supporting ability and living environment supporting ability, etc. Mostly, it is the experts and brainstorming that assess and evaluate the importance of the foregoing factors.

\subsection{Analysis of Methods in Evaluating Leisure Sports Majors' Innovation Ability}

At present, there are uniform and specified evaluation methods. Main methods as follows:

(1)Level method. It is to classify the students in accordance with their 1nnovation abilities into to three levels from low to high: I level, II level and III level. This method is subjective.

(2)Binomial evaluation method. It is to divide innovation factors into intelligent factor and non-intelligent factor and to conduct fuzzy evaluation after relevant topics design and research. This method is easy to operate, but result is not clear.

(3)Comprehensive evaluation method. Starting from the reality, this method is to assess the students' hands-on ability from heir awareness, skills, personalities and practical work. It is a multiple-factor comprehensiye evaluation.

\subsection{Defining Index and Rates of Evaluation}

After consulting a number of books abouteisure sports majors' innovation ability on the basis of computer use and searching intormation on China Journal Net and China National Knowledge Infrastructure, the author used the methodized documents to analyze and research this evaluation system. Using mathematical statistics, the author concluded the relevant index affecting improying of leisure sports majors' innovation ability. Using the method of expert discussion, Delphi and brainstorming as well as telephone conversation, on-line talking and expert interview, the author made further study and amendment on this paper after comparing and researching their views and suggestions. Then the author put foy ard the evaluation index and defined the rates of evaluation. Here is the flowchart: 


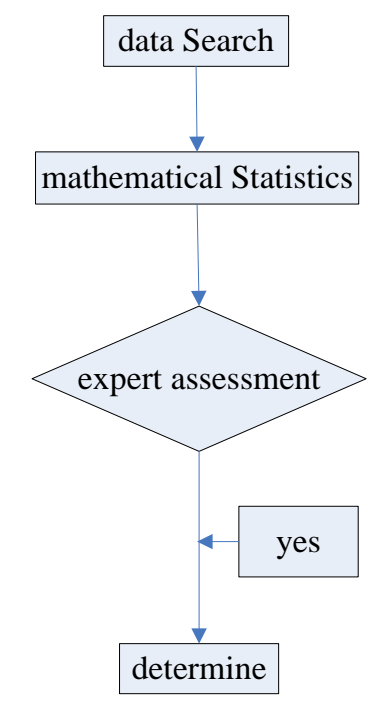

Figure 1. Evaluation Index Flowchart

\subsection{Setting Gray Evaluation Model}

(1) Index matrix of gray evaluation model. Suppose the number of experts to make evaluation is " $\mathrm{m}$ ", score of the $m$ th expert's evaluation of the $n$th index is denoted by $a_{m n}$, There are $\mathrm{n}$ evaluation index. Final evaluation matrix is denoted by $\mathrm{A}$ as follows:

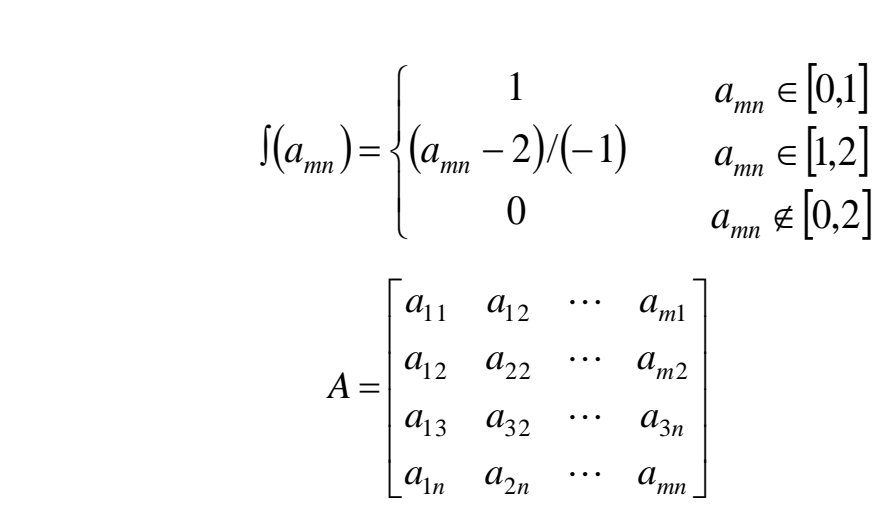

(2) Defining the gray number whitenization weight function of gray evaluation model. When the eyaluation rate is "bad" $(t=1)$, we set the value range of gray number as $[0,1,2]$, so the final whitenization weight function hereof is:

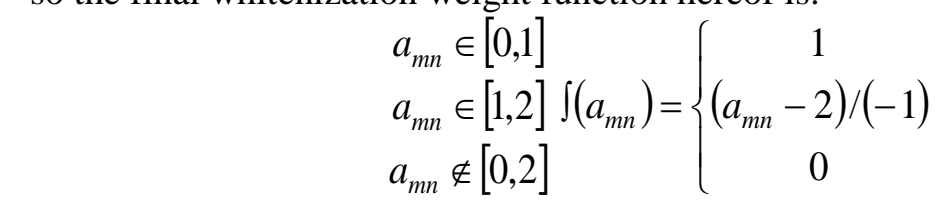

When the rate is "moderate" $(\mathrm{t}=2)$, we set the value range of gray number as $[0,2,4]$, so the final whitenization weight function hereof is:

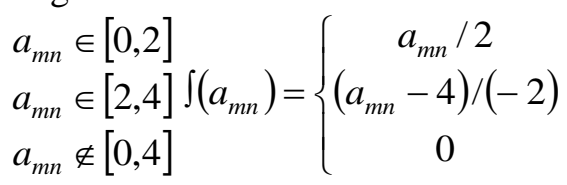

When the rate is "good" $(\mathrm{t}=3)$, we set the value range of gray number as $[0,4,8]$, so the 
final whitenization weight function hereof is:

$$
\begin{aligned}
& a_{m n} \in[0,4] \\
& a_{m n} \in[4,8] \\
& a_{m n} \notin[0,8]
\end{aligned} \int\left(a_{m n}\right)=\left\{\begin{array}{c}
a_{m n} / 4 \\
\left(a_{m n}-8\right) /(-4) \\
0
\end{array}\right.
$$

(3)Matrix of gray evaluation weight computing. Based on whitenization function $\int\left(a_{m n}\right)$ and evaluation index $a_{m n}$, the gray evaluation index of $h$ th expert's identifying index is:

$$
w_{m n}=\sum_{h=1}^{k} \int\left(a_{m n}\right)
$$

From the forgoing formulas as well as the views and suggestions of $h$ experts, so the gray evaluation index can be denoted by:

$$
W=\sum_{1}^{q} w_{m n}
$$

After normalizing the foregoing on relevant software we can get the gray evaluation weight of evaluation index as follows:

$$
\lambda=\frac{w_{m n}}{W}
$$

Based on all evaluation indexes we have seh we can get the vector of gray evaluation weight as follows:

$$
\lambda_{i j}=\left(\lambda_{1}, \lambda_{2}, \cdots, \lambda_{l}\right)
$$

In terms of the foregoing vector, we can get the gray evaluation weight matrix:

$$
\text { Q } V=\left[\begin{array}{cccc}
\lambda_{11} & \lambda_{12} & \cdots & \lambda_{1 l} \\
\lambda_{21} & \lambda_{22} & \cdots & \lambda_{2 l} \\
\vdots & \vdots & \vdots & \vdots \\
\lambda_{l 1} & \lambda_{l 2} & \cdots & \lambda_{l l}
\end{array}\right]
$$

(4)Defining standard of comprehensive evaluation. Comprehensive evaluation standard is scientific and just in nature. It ean comprehensively and objectively reflect good or bad of the result. It is to combine Analytic Hierarchy Process with Gray Theory to set the sequence on a two-dimension level according to good or bad.

$$
V=D \times F^{T}
$$

Here, D represents the maximum gray rate; $\mathrm{F}$ represents the quantitative value of gray rate; vectôr is denoted by

$$
F=\left(a_{1}, a_{2}, \cdots, a_{n}\right) \text { 。 }
$$

\section{Intelligent Evaluation of Leisure Sports Majors' Innovation Ability-Taking Hebei Institute of Physical Education as Example}

The indexes are set as follows in accordance the standard of leisure sports majors' innovation ability system under computer use, differences among indexes as well as the authoritativeness of experts and individuality of indicator: 
Table 3. Index Tables at All Levels

\begin{tabular}{ll}
\hline Level indicators & Secondary indicators \\
\hline & problem found \\
& Maverick \\
& Cross-knowledge \\
Creativity & Knowledge Innovation \\
& logical thinking \\
& Creativity \\
& Unique level \\
& Outcome of the activity \\
\hline
\end{tabular}

Meanwhile, in accordance with views and suggestions of experts as well as the actual situation, weight value of different levels are defined as follows:

Table 4. Index Weight Value Table

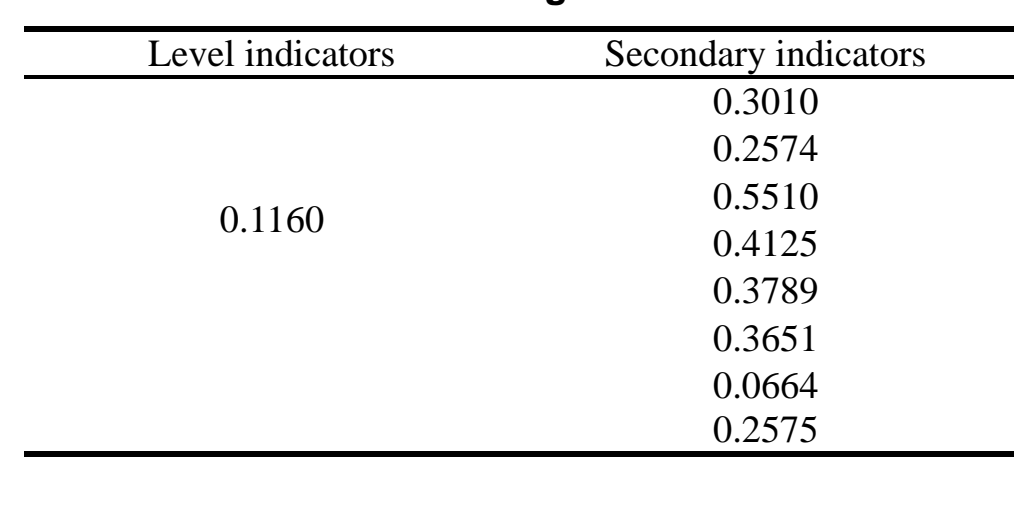

From the structure of evaluation moder, using mathematical statistics, we can get the sample matrix by comparng the results of level indicators and secondary indicators:

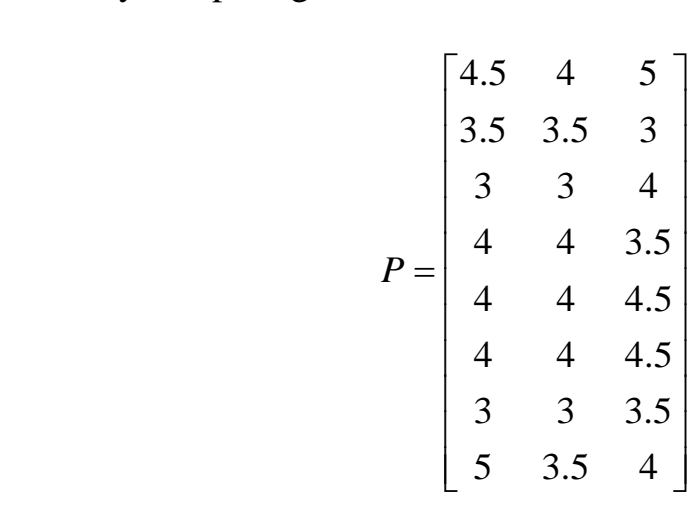

(1) here is the computing of gray evaluation model index. From above, evaluation rates are classified into three levels, namely, "bad", "moderate" and "good". As for the modern leisure sports innovation ability indicator, the ath evaluation index of gray evaluation is:

(1) When $\mathrm{t}=1$, the index is:

$$
w_{11}=\int_{1}\left(a_{11}\right)+\int_{1}\left(a_{12}\right)+\int_{1}\left(a_{13}\right)=0+0+0=0
$$

(2) When $\mathrm{t}=2$, the index is:

$$
w_{12}=\int_{2}\left(a_{11}\right)+\int_{2}\left(a_{12}\right)+\int_{2}\left(a_{13}\right)=0.5+0.56+1.23=2.31
$$

(3) When $\mathrm{t}=3$, the index is:

$$
w_{13}=\int_{3}\left(a_{11}\right)+\int_{3}\left(a_{12}\right)+\int_{3}\left(a_{13}\right)=1+0.67+0.9=2.57
$$


To sum up, the overall evaluation index is:

$$
w=w_{11}+w_{12}+w_{13}=0+2.31+2.57=4.88
$$

(2)and the gray evaluation hereof weight is:

(1) When $\mathrm{t}=1, \lambda_{11}=\mathrm{x}_{11}^{\prime} / x_{11}=0$

(2) When $\mathrm{t}=2, \lambda_{12}=\mathrm{x}_{{ }_{12}} / x_{11}=2.31 / 4.88=0.4733$

(3) When $\mathrm{t}=3, \quad \lambda_{13}=\mathrm{x}_{13} / x_{11}=2.57 / 4.88=0.5266$

(4) From above, the vector of modern leisure sports innovation ability over every rates weight is:

$$
\lambda=\left(\lambda_{11}, \quad \lambda_{12}, \lambda_{13}\right)=(0,0.4733,0.5266)
$$

In terms of secondary indicators, we set the overall evaluation index as:

$$
V=\left[\begin{array}{lll}
0 & 0.4667 & 0.2398 \\
0 & 0.6723 & 0.3425 \\
0 & 0.7643 & 0.7532
\end{array}\right]
$$

In conclusion, the final value of comprehensive evaluation in this model is:

According to the overall evaluation weight of the model, we can get the result of comprehensive evaluation as follows:

$$
Z^{T}=V \cdot \lambda^{T}=\left[\begin{array}{lll}
0 & 0.4667 & 0.2398 \\
0 & 0.6723 & 0.3425 \\
0 & 0.7643 & 0.7532
\end{array}\right]\left(\begin{array}{c}
0 \\
0.4733 \\
0.5266
\end{array}\right)=\left(\begin{array}{l}
0.4356 \\
0.6522 \\
0.6356
\end{array}\right)
$$

$$
G=Z \cdot T^{T}=(0.4356,6.6522,06356)\left(\begin{array}{l}
1 \\
2 \\
3
\end{array}\right)=4.5671
$$

After comparing the foregoing result with that of defined gray evaluation model, we can conclude that:

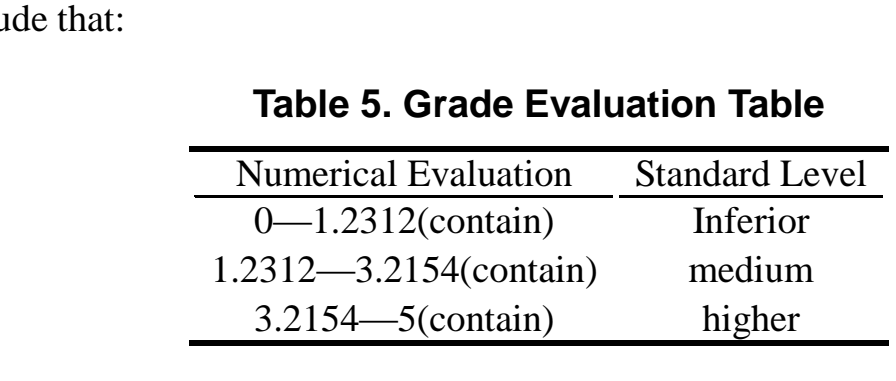

From the foregoing result, we know that the comprehensive value of HeBei Institute of Physical Education is 4.4571, which is "good". We can conclude that in this institution, students' innovation studying ability on modern leisure sports stay in a relative high level, with certain development potential. The institution can be a example for others to follow. However, they still have a long way to go.

\section{Conclusion}

This paper is to study the evaluation of leisure sports majors' innovation ability based on computer use, which stays in a relatively low level and needs further development to keep up with the status, by researching the status of artificial intelligence at home and broad under the current economic, cultural and leisure development. The author set indexes and rating evaluation standard using gray evaluation model to assess the innovation ability of HeBei Institute of Physical Education. After summarizing and normalizing relevant weight, the author made comprehensive evaluation and concluded the rate of "good" in students' innovation ability in this institution. This method laid a 
foundation for relevant evaluations in other universities as well as the study of AI theory. It will also act as a guiding principle for relevant practices. The model hereof is of great importance for the development of China's leisure industry.

\section{Development Trends}

\subsection{Diversification Of Leisure Sports}

Based on computer use, leisure sports innovation ability is developing and being applied by means of massive distribution, expert collaboration, parallel reasoning, systematic developing and artificial intelligence. It involves various areas such as expert system, machine learning, neutral network and artificial life, which are essential in propelling the development of S\&T and relevant industries.

\subsection{Professionalization of Leisure Sports}

In teaching of leisure sport innovation ability, stresses were laid more on market in major development, innovation in model establishment, practice in sectors connection, cultivation in talent fostering and employment in direction pinpointing. Besides, the combination of curriculum and social factors has brought the mnovation and application ability on the basis of computer use into full play.

\subsection{Popularization of Leisure Sports}

Leisure sports tends to focus more on setting plans avaiable for fitness of all people, raising the objective in the development of mass fitness, improving people's sports awareness and physical and mental Gealth, changing people's lifestyles, setting up a correct sports attitude, embodying the value of leisure sports innovation ability and meeting the needs of the building leisure sports industry.

\subsection{Extensiveness of Leisure Sports}

In its development Deisure sports are constantly updating absorbing new knowledge and theories. Its stidies, both on practice and theory, continue to deepen. Research scope continues to expand, which includes not only economy but also other areas as civilization and environmen

\subsection{High Developing Speed of Leisure Sports}

The development of leisure sport has become an important part of the people's life in modern times. It develops quickly with more people involved. The proportion of application and consumption in sports are growing, the degree of development has largely exceeded that of other areas. Sports and leisure industry occupies a considerable proportion in the social applications.

\section{Development Suggestions}

(1)To Optimize the Structure of Leisure Sports Innovation Ability Curriculum

We need to ensure a proper course arrangement and outstanding course features; coordinate the courses and integrate their functions; collaborate macro and micro structure and follow the basic, overall, proportional and optional principles of constructing course. We need to properly handle the relationship between optional and compulsory courses, subject courses and technical courses, the dominant curriculum and hidden curriculum, national course and local courses. In teaching, we need to alter the original status with monotonous methods and fuzzy objectives, raise the students' desire for knowledge, and to strengthen professional courses. In terms of training methods, we need to change the 
status of private lesson unsound innovation system and closed teaching process, properly conduct talents cultivation and innovation ability application. Meanwhile, we need to focus on cultivation results, and create a good environment.

\section{(2)To Improve the Implementing Environment of Curriculum}

We need to establish qualified sports venues and equipment, open relevant courses and to better manage the users' environment of culture, public opinions and economy. We need to strengthen software construction, namely, to strengthen the implementation environment of the software and deepen its construction. We need to keep the users and coaches a positive attitude curriculum reform and let them realize its value and significance to their own growth.

\section{(3)To Diversify Leisure Sports Projects}

We need to establish and develop self-constructed profit and non-profit leisure sports projects, strive to establish projects with both organizational and non-organizational feature, ensure the smooth development of sports industry in collaborating with market, information and policies. Meanwhile, we need to improve and innovate sports theories as well as to develop new projects while intensifying the exploration and utilization of sports resources.

\section{(4)To Use Multiple Means to Develop Leisure Sports}

We can play leisure sports no only indoors but also outdoors and other places as wide. Leisure sports also include golf, outdoor survival and mountaineering. So we need to establish a trans-regional, multi-industry and inter-company leisure sports group.

\section{(5)To Take Advantage of Favorable Conditions}

Schools need to provide favorable conditions for students' development enhance the construction and use of sports venues and improve the using efficiency of sports equipment. Relevant departments need-to provide fachities so as to provide sufficient materials for coaches and users. Science and technology departments need to introduce and utilize related technologies andequipment, optimize the allocation of resources, bring in advanced facilities from overseas, make full use of social resources and provided technical support leisure sports mdustry

\section{References}

[1] J. Dumazedier, "Toward a Society of Leisure", New York: The Free Press, (1967), pp. 16-17

[2] E. L. J. Thom and L Burton, "eds Leisure Studies: Prospects for the Twenty-first Century", Venture Publishing, Inc, vol. 8, no. 13,(1999).

[3] R. F. Mull, "Recreational Sports Managemait", The Athleticlnstitute, (1997).

[4] L. Zhang, "The Way to Wealth and the Way to Leisure: The Impaet of College Edueation on Graduates' Eamings and Hours of work", Res High Educ, (2007).

[5] C. R. Edginton, "Leisure and Life Satisfaction", (1998).

[6] J. Dumazedier, Toward a Society of Leisure", New York: The Free Press, (1967), pp. 16-17.

[7] G. Atkinson, "Thomas Reilly", Sport Leisure and Ergonomics VI, Ergonomics, no. 4, (2009).

[8] M. Fullan, "The new meaning of educational change", New York: Teachers College Press, vol. 63, (1991), pp. 125-127.

[9] P F. Oliver, "Developing the curriculum", New York: Harper Collins Publishers, (1976), pp. 12-25.

[10] K. R. Muller, S. Mika and G. Ratsch, "An introduction to kernel-based learning algorithms", IEEE Trans. on Neural Networks, vol. 12, no. 2, (2001), pp. 150-165.

[11] J. Mundy and L. Odum, "Leisure Education-Theory and Police", New York, NY: John Wiley and Sons, pp. 1-3.

[12] N. Hanley, W. D. Shawa and E. Robert, "The new economics of outdoor recreation", Cheltenham, Glos, UK; Northhampton, Mass.E, Elgar, (2003).

[13] D. K. Stotlar, "Vertical integration in sport", Journal of Sport Management, vol. 14, no. 1, (2000), pp. $1-7$.

[14] A. Balmford, J. Beresford, J. Green, R. Naidoo, M. Walpole and A. Manica, "A global perspective on the trends in nature-based tourism", PLoS Biology, vol. 7, no. 6, (2009), pp. 77-82.

[15] T. D. Glover and T. Burton, "A Model of Alternative Forms of Public Leisure Services Delivery, in Leisure Management: Issues and Applications, M. F. Collins and I.S. Cooper.CAB International, 1998.

[16] [16] Thomas Hinch and James Higham.Sport tourism development", Clevedon. Buffalo: Channel Veiw Publications, (2004). 
[17] K. Roberts, "The leisure industries", New York Palgrave Macmillan, (2004).

[18] K. R. Muller, S. M. Mka and G. Ratsch, "An introduction to kernel-based learning algorithms", IEEE Trans on Neural Networks, vol. 12, no. 2, (2001), pp. 181-201.

[19] K. Littleton, S. Taylor and A. Eteläpelto, "Special Issue Introduction: Creativity and Creative Work in Contemporary Working Contexts", Vocations and Learing, vol. 5, no. 1, (2012), pp. 1-4.

\section{Author}

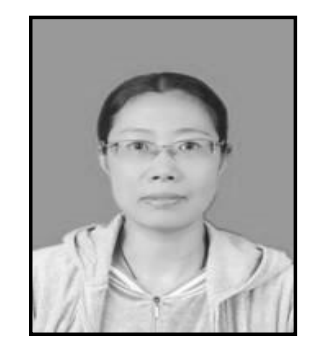

Li zhishuang, She is the vice professor of Shijiazhuang Tiedao University. Her research direction is the Physical Education and Training.

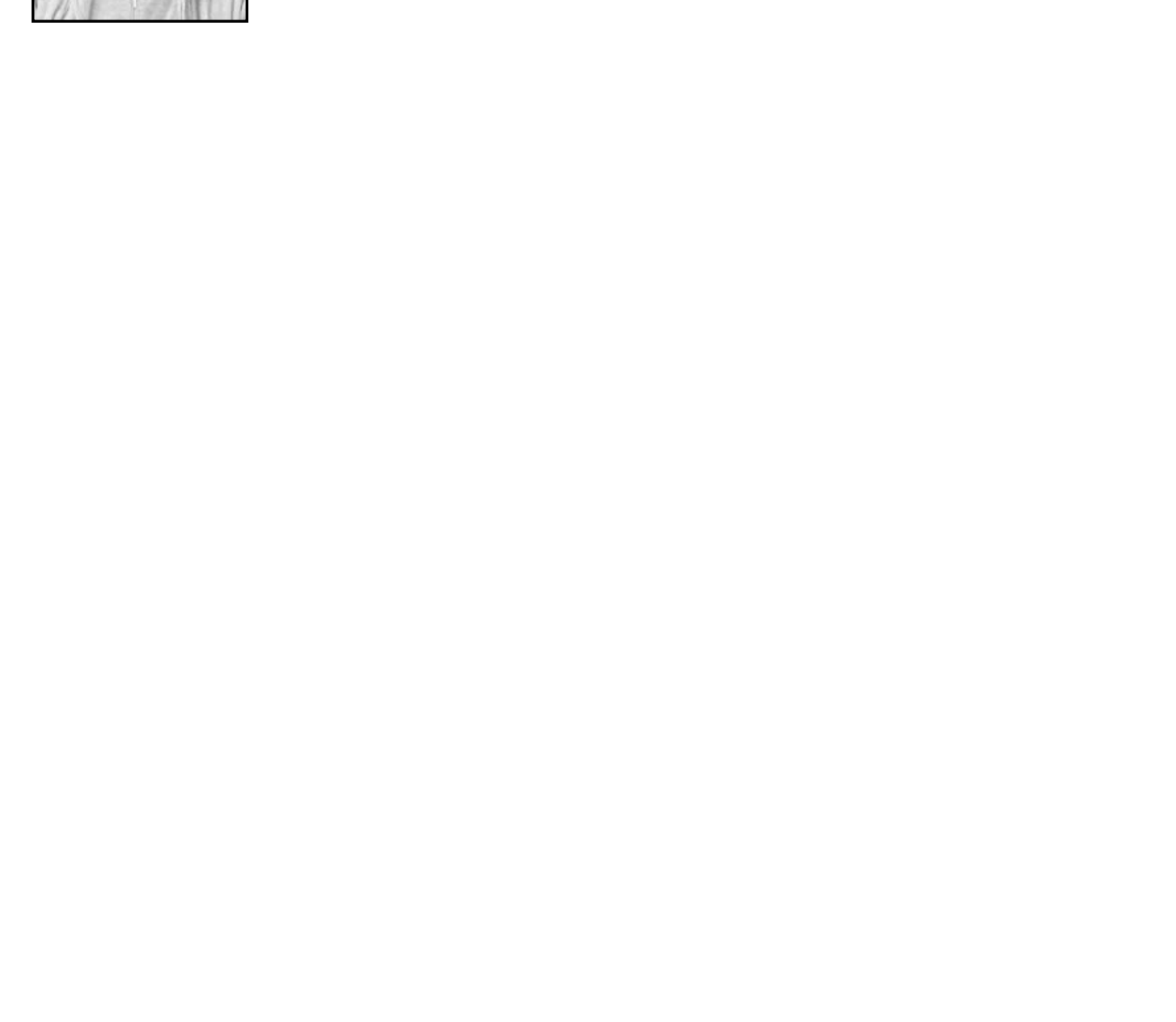

